\title{
THREE-DIMENSIONAL EVALUATION OF MARGINAL BONE RESORPTION ASSOCIATED WITH FLAP AND \\ FLAPLESS PLACEMENT OF IMMEDIATELY LOADED IMPLANTS RETAINING MANDIBULAR OVERDENTURES WITH RESILIENT STUD ATTACHMENTS. ONE YEAR RANDOMIZED CONTROLLED CLINICAL TRIAL
}

\author{
Samer Mostafa Ali*
}

\begin{abstract}
Purpose: This study was carried out to evaluate Three-Dimensional marginal bone resorption with flap and flapless placement of immediately loaded implants retaining mandibular overdentures with locator attachments.
\end{abstract}

Materials and methods: Ten edentulous patients ( 6 males and four females, with an average age of 59 years) complaining of lack of retention of mandibular dentures received two implants in the canine positions of the mandible using either flap (group 1) or flapless (group 2) surgical approach. All implants were immediately loaded with locator retained mandibular overdentures. Cone beam CT was used to measure Three-Dimensional bone loss at mesial, distal, buccal and lingual surface of each implant. Measurements were made at baseline, six and 12 months later after delivery.

Results: The survival rate was $90 \%$ and $100 \%$ for flap and flapless groups respectively. For all implant surfaces, flap group showed significant higher bone resorption than flapless group. After 12 months, the highest bone loss occurred at the mesial surface and the lowest bone loss occurred at the buccal surface in the flap group. For flapless group, the highest bone loss occurred at buccal surface and the lowest bone loss located at lingual surface. For all implant surfaces in both groups, marginal bone loss after 12 months was significantly higher than the values after six months.

Conclusion: Within the limitations of this study, the flapless surgical approach is recommended for locator retained mandibular overdentures than the flap approach as it was associated with reduced marginal bone loss after 12 months.

* Associate Professor, Removable Prosthodontics Department Faculty of Dentistry, October University For Modern Science and Arts. Giza, Egypt. 


\section{INTRODUCTION}

The use of two implants to retain and stabilize mandibular overdentures is now considered a routine discipline in management of edentulous patients as it improves the retention and stability of overdentures, increases chewing efficiency, reduces the pain and discomfort during mastication and improves patient satisfaction and oral health-related quality of life $\mathrm{e}^{1,2}$. Implant retained overdentures are alternative to fixed prosthesis if patients cannot afford increased costs, in medically debilitated patients to avoid bone grafting procedures or if prosthesis requires excessive cantilevers to obtain necessary occlusal contact and in patients with unfavorable arch relationships due to advanced resorption ${ }^{3}$. Such overdentures use of different retention systems that are broadly categorized as splinted or unsplinted. The splinted attachment systems are the bar attachments while the unsplinted systems comprise ball-types, magnets, telescopic crowns or resilient stud (Locator) attachments ${ }^{4}$. When using two implants to retain overdentures the attachment mechanism should permit vertical and hinge movements of the overdenture to allow overdenture rotation during function and enhance twist-free load transmission to the implants ${ }^{5}$. The unsplinted attachments had several advantages over the splinted ones such as reduced prosthetic space within the denture base, reduces the cost, ease of cleaning and performing oral hygiene and reduced technical complications ${ }^{6,7}$. The selection of appropriate attachment depends on several patient factors such as interarch and restorative spaces, ridge shape, amount of retention and stability desired, implant angulation, ease of maintenance, patient compliance, repair and cost ${ }^{8}$. Moreover, the attachment should provide optimum force distribution around supporting implants to allow bone loading within physiologic levels to avoid bone resorption around implants ${ }^{9}$. The difference in displacement between the implant and soft tissue must be considered and the attachments should provide equal load distribution between the implants in the mucosa to avoid implant overloading ${ }^{10}$.

The resilient stud (Locator attachment) is the most popular attachment system used in the last decade. Locators are resilient, self-seating and have double retention (comes from their internal and external frictional flanges) and color-coded with different retention values ${ }^{7,}{ }^{11}$. Moreover locators uses a straight abutment and relies on the male component, which lies within the removable prosthesis, to resolve any problems related to angulation $^{12}$. Therefore, it can compensate for implant inclination up to 40 degree ${ }^{13}$. In addition, the reduced vertical height of locators allow them to be used with limited inter-arch distance to avoid over contouring of the prosthesis, excessive occlusal vertical dimension, patient dissatisfaction ${ }^{14}$ and denture base deformation and fracture ${ }^{15}$

Marginal bone resorption around implants is a multifactorial condition that may be affected by occlusal loading, bacteria and plaque retention in peri- implant areas ${ }^{16}$. Marginal bone loss is affected by the surgical technique for implant placement such as flap and flapless surgery ${ }^{16}$. The flapless surgery has several advantages such as minimal surgical trauma, short surgical time, decreased the postoperative pain, edema and patient comfort and rapid postsurgical healing ${ }^{17,18}$. The flap surgical approach provides good visualization of anatomical structures, ridge shape and landmarks at implant placement which reduce the risk of bone fenestration and perforation but also associated with increased postoperative edema and discomfort 19,20

Immediate loading of implants with mandibular overdentures after surgery provide patients with immediate restoration of mastication and aesthetics and also avoid the use of conventional dentures during the healing period. However, it may result in micromotions at implant/bone interface thus interfering with the healing process ${ }^{21}$. It is possible that non-splinted implants may be negatively 
affected by immediate loading because the load is not shared between implants, which may influence marginal bone resorption ${ }^{22}$.

Radiographic evaluation of the peri-implant bone, in addition to assessment of several clinical parameters, became one of prerequisites for estimation of implant success Consequently, there is a current emphasis on the significance of peri-implant bone $\operatorname{loss}^{23}$. However, evaluation of marginal bone resorption usually made with the 2- dimensional periapical radiographs which allow evaluation of mesial and distal proximal bone loss only with neglection of buccal and lingual bone resorption. Cone-beam computed tomography (CBCT) provides three-dimensional images cross sectional images $^{24}$ that allow visualization of the bucco-lingual bone around the implants ${ }^{25}$. Several studies reported a good implant survival for two immediately-loaded unsplinted implants with Locator ${ }^{26,27}$ attachments. However, the evaluation of flap and flapless surgical approach for implant placement to support immediately loaded mandibular overdentures was not a concern in regular diameter implant and was performed with narrow diameter implant only. Therefore, the aim of this study was to evaluate and compare 3-dimensional marginal bone resorption associated with flap and flapless placement of immediately loaded implants retaining mandibular overdentures with locator attachments.

\section{MATERIALS AND METHODS}

A convenient sample of 10 completely edentulous participants ( 6 males and four females, with an average age of 59 years) were selected for this randomized trial from the outpatient clinic attending the Prosthodontic Department. The included participants were complaining from insufficient stability and retention of their mandibular conventional dentures. The included participants were required to have 1) sufficient bone height and width in the canine regions of the mandible to receive standard implants (Tiologic, Dentarum, Germany) of at least $11 \mathrm{~mm}$ in height and $3.7 \mathrm{~mm}$ in width (class IV-VI Cawood and Howell $\left.{ }^{28}\right)$. A preoperative cone beam CT was made to verify bone volume at proposed implant sites. 2) sufficient bone quality and density at canine areas (classes I-III Lekholm and Zarb ${ }^{29}$ ), 3) sufficient restorative space, 4) at least one year elapsed rom the last extraction. The participants were excluded if they had 1) Kinfe edge (or thin) ridges, 2) radiation therapy to head and neck region or chemotherapy, 3) systemic diseases that may interfere with surgery or may affect osteointegration or bone metabolism such as diabetes mellitus, liver disease, or heart disease, and 4) uncooperative patients. The participants were randomly assigned into two groups jointed by gender to ensure equal sex distribution between groups (three males and two females in each group). Randomization was performed using random numbers included in Excel spreadsheet. Group 1 included 5 participants who received two implants in canine areas using conventional one stage flap surgical technique. Group 2 included 5 participants who received two implants using one stage flapless surgical approach. All implants were immediately loaded with locator retained mandibular overdentures at the same day of surgery. Detailed the protocol and objectives of the study were prescribed to each participant before signing an informed consent. The study plan was approved by the ethical committee of the faculty.

\section{Detailed surgical and prosthetic procedures}

A new conventional maxillary and mandibular denture was constructed for each participant. After final impressions were registered, recorded bases were constructed and used to record maxillomandibular relations in centric and eccentric positions using static interocclusal records. Bilateral balanced occlusion was made using semi-anatomic acrylic teeth. Try in was completed under the dentures were processed in usual manner. The 
dentures we are delivered to the participants after performing the necessary occlusal and margin adjustment, and the patients were instructed to wear the dentures for at least two months to enhance neuromuscular adaptation.

For all patients, the preoperative cone beam CT (i-CAT device; Imaging Sciences Intl) was used to evaluate bone at proposed implant sites and to detect the proper implant lengths and widths. For group 1, the mandibular denture was duplicated into heat cured acrylic resin with metal tubes attached at canine areas to be used as a surgical guide. A mid crestal incision was made from premolar area on one side to premolar area on the other side. Then a full-thickness mucoperiosteal flap was raised. Using the surgical guide, two implants (Dentaurm, Germany) were inserted in the canine areas parallel to each other's using successive drilling. Locator abutments of adequate mucosal thickness were connected to the implants and the flap was closed around the abutments using interrupted sutures. Rubber dam sheets were adapted around locator abutments over the sutures and white blocking rings were attached to the abutments to prevent excess acrylic resin (Acrostone, Egypt) to enter undercuts or contact the abutments. The processing inserts of locator attachments were included in their metal caps and snapped on locator abutments. The mandibular dentures were hollowed opposite to each locator attachment and lingual events were made to allow escape of excess acrylic resin. Care should be taken to ensure that there was no contact between the locator housings and the fitting surface of the mandibular dentures. The locator housings were picked up to the mandibular dentures using autopolymerized acrylic resin while the patients closed in centric occlusion. Excess acrylic resin was removed and the dentures were published.

For group 2, the implants were inserted using a mucosal supported surgical template and computer guided flapless surgery. The mandibular denture was duplicated and radiopaque gutta purcha markers were attachment to the labial, buccal, and lingual polished surface of the duplicate denture to be used as a radiographic template. For each participant, the dual scan protocol was performed; one scan for the denture only and the other scan while the patient wearing the denture. The two scans we are overlapped then the resultant images we reformatted. Implant positions and orientations were planned using the software accompanied the CBCT scans (OnDemand; CyberMed Inc). The plan was used to construct a mucosal supported Sterolithographic surgical guide using prototyping technology. The guide contains sleeves fixed it over implant positions. Under local anesthesia the guide was fixated into the mandible using the cortical pins while the patient close on rubber base interocclusal record. Using the surgical kit that accompanied the surgical guide (In2guide), two circular incisions were made using a tissue punch. Then implant osteotomies were made using successive drills of increasing diameters that precisely fit the sleeves

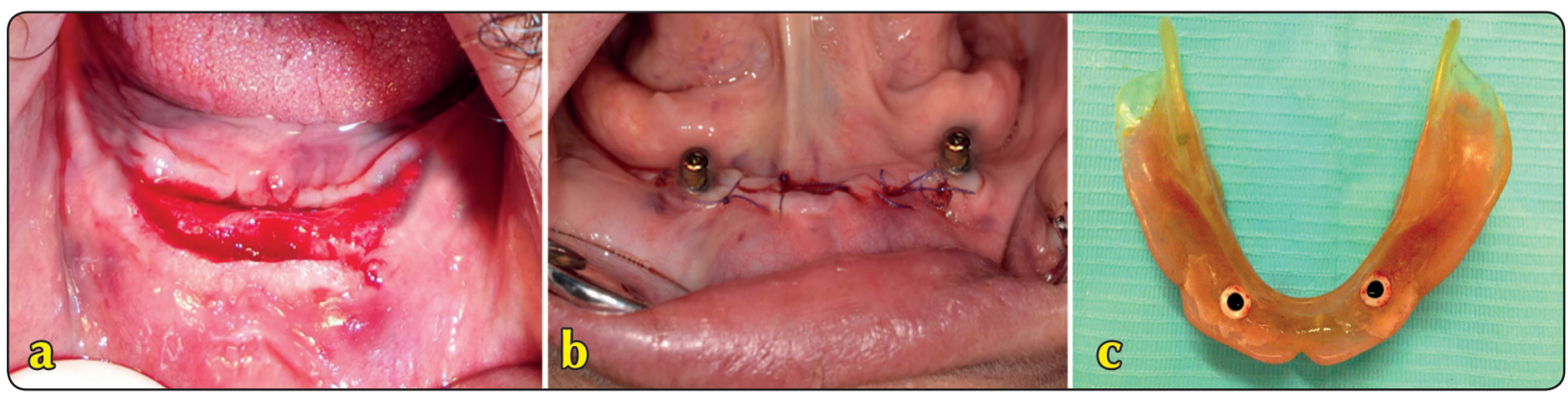

Fig. (1) Flap group; a; mid crestal incision and implant placement parallel to each other, b, locator abutments screwed in implants and flap closure, c, pick up of the locator housing the fitting surface of the overdentures. 
of the guide. The implants were inserted in the prepared osteotomies and locator abutments were connected to the implants. As Group 1, white blocking rings were attached to the abutments and locator housings were snapped over the abutments. The housings were then picked up to the mandibular overdentures similar to Group 1. For both groups, black processing inserts were replaced with blue nylon inserts (light retention). The dentures we are delivered to participants two immediately loaded the implants with instructions on oral hygiene instructions. Occlusal adjustments were made by selective grinding to ensure that there is no occlusal interference in centric and eccentric positions. For group 1, sutures were removed after two weeks and the denture were relined to ensure good adaptation to underlying mucosa.

\section{Measurement of Three-Dimensional marginal bone loss}

For each participant, Cone beam CT was made at base line (immediately after denture delivery), 6 months (6m), and 12 months (12m) after denture delivery. All exposure conditions were standardized for all patients such as acquisition time, voxel size and slice thickness. The images were stored as DICOM (Digital Imaging and Communications in Medicine) files. The bone loss was measured at mesial, distal, buccal and lingual surface of each implant. Using a curve tool of the software (OnDemand), each implant was bisected mesiodistally from the occlusal view. After image reconstruction cross sectional and panoramic images for each implant was obtained. Mesial and distal peri-implant bone resorption was measured at the panoramic images. Buccal and lingual bone resorption was calculated at cross sectional images (fig). To calculate marginal bone resorption, the vertical distance from implant abutment junction (point A) to the bone contact with implant (point B) was measured to give bone level ${ }^{30}$. Bone loss was calculated by subtracting bone levels at $6 \mathrm{~m}$ and $12 \mathrm{~m}$ from bone levels at base line. The bone loss measurement for right and left canine implants were averaged and the mean was used for statistical analysis. The bone measurements were performed three times using different examiners to verify the inter-examiner reliability of obtained measurement.

\section{Statistical analysis}

The data were analyzed using SPSS ${ }^{\circledR}$ software version 25 (SPSS Inc., Chicago, IL, USA). Shapiro Wilk test was used to detect the normal distribution of the data. The data was parametric and normally distributed. A (Cronbach) test was used to test the inter-examiner reliability. The data was parametric and described as mean and standard deviation. Repeated measures ANOVA was used for compare marginal bone loss between groups, implant surfaces (mesial, distal, buccal and lingual), and observation times followed by Tukey test for multiple pairwise comparisons. The level of significance was adjusted at $5 \%$.

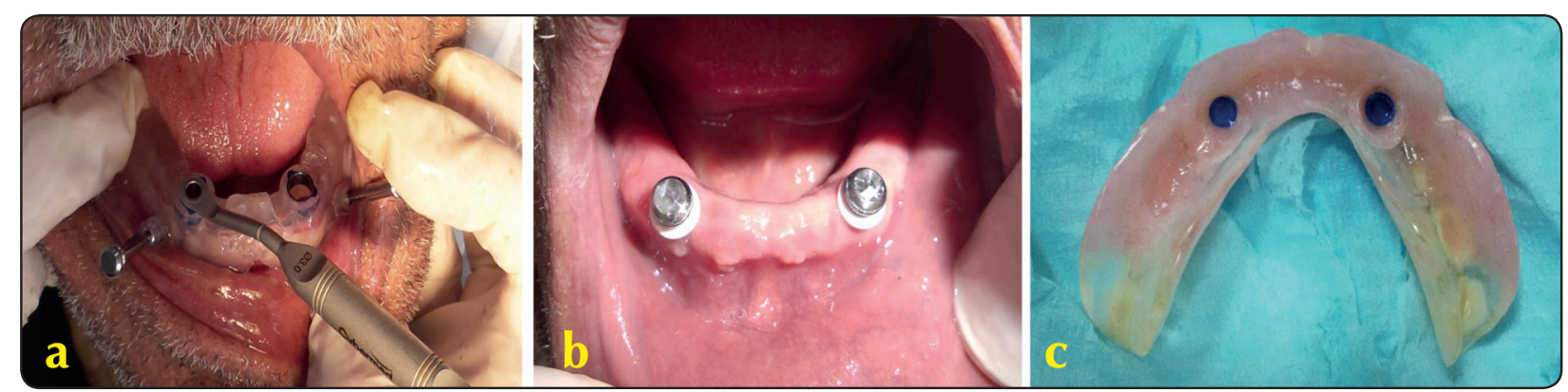

Fig. (2) Flapless group; a; implant placement using mucosal supported stereolithographic surgical template and the associated surgical kit, b; metal caps snapped on locator abutments and white blocking rings around the abutments, c; replacement of black inserts with blue nylon inserts 


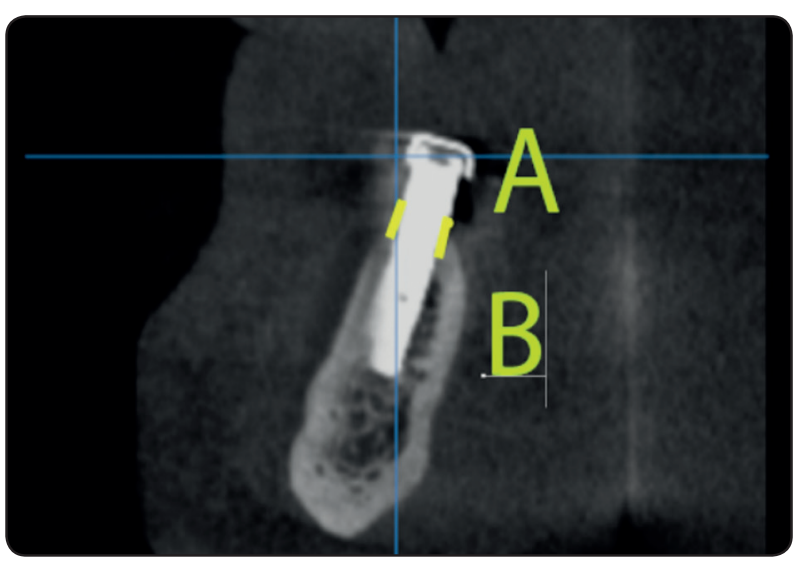

Fig. (3) measurements of buccal and lingual marginal bone resorption in the cross-sectional images of the implants. A; implant abutment connection, B; bone to implant contact.

\section{RESULTS}

One implant failed in each group as a result of immediate loading (within the first three months) and flap group and no implant failures occurred in flapless group resulting in $90 \%$ and $100 \%$ survival rate in both groups respectively. The coefficient of variation for inter-examiner reliability test was .80 which indicate that all measured values of bone resorption were reliable (table 1).

Comparison of marginal bone loss between groups and implant surfaces at 6 and 12 months is shown in table2. For all implant surfaces, the flap group showed a significantly higher bone resorption than the flapless group after 6 months $(\mathrm{P}=.048, .003$, .049 , and .002 for mesial, distal, buccal and lingual surfaces respectively) and 12 months $(\mathrm{P}=.001, .029$, .047 , and .001 for mesial, distal, buccal and lingual surfaces respectively). Also, the total marginal bone loss (occurred in oral implant surfaces) was significant higher in the flap group compared to flapless group $(\mathrm{P}=.004$ and .001 after 6 and 12 months respectively).

For each group comparisons between different implant surfaces at 6 and 12 months is presented in the same table. After six months, there was no significant difference in marginal bone loss between implant surfaces for flap group. However, for flapless group, there was a significant difference between implant surfaces with buccal surface showed the highest marginal bone loss followed by distal and lingual surfaces then mesial surface. There was no significant difference between distal, lingual and mesial surfaces. After 12 months, there was a significant difference between implant surfaces for both groups. For flap group the highest bone loss occurred at mesial surface followed by lingual surface then distal surface with two significant difference. The lowest marginal bone loss occurred at buccal surface. For flapless group, the highest bone loss occurred at buccal surface followed by distal and mesial surface and the lowest bone loss located at lingual surface. A statistically insignificant difference $(\mathrm{P}>0.05)$ was observed between the mesial, distal and lingual surfaces. Multiple comparison between implant surfaces for both groups at six months and 12 months is presented in table 1 and in figure 4 and 5 respectively.

Comparison of marginal bone loss between 6 and 12 months for all implant surfaces for flap group and flapless groups are shown in figure 6 and 7 respectively. For all implant surfaces in both groups, marginal bone loss after 12 months was significantly higher than values after six months. 
TABLE (1) Intraclass correlation coefficient of marginal bone loss for both groups

\begin{tabular}{|c|c|c|c|c|c|c|c|c|c|}
\hline \multicolumn{2}{|l|}{ Group } & \multicolumn{4}{|c|}{6 months } & \multicolumn{4}{|c|}{12 months } \\
\hline & & Mesial & Distal & buccal & lingual & Mesial & Distal & buccal & lingual \\
\hline \multirow[t]{2}{*}{ ExaminerA vs. B } & Flap & $.94 *$ & $.95 *$ & $.92 *$ & $.91 *$ & $.95 *$ & $.93 *$ & $.92 *$ & $.92 *$ \\
\hline & Flapless & $.95^{*}$ & $.98 *$ & $.94 *$ & $.94 *$ & $.94 *$ & $.95^{*}$ & $.94 *$ & $.97 *$ \\
\hline \multirow[t]{2}{*}{ ExaminerB vs. C } & Flap & $.97 *$ & $.89 *$ & $.93 *$ & $.95^{*}$ & $.93 *$ & $.98 *$ & $.93 *$ & $.89 *$ \\
\hline & Flapless & $.97 *$ & $.84^{*}$ & $.92 *$ & $.96 *$ & $.99 *$ & $.94 *$ & $.92 *$ & $.89 *$ \\
\hline \multirow[t]{2}{*}{ ExaminerA vs. C } & Flap & $.92 *$ & $.91 *$ & $.88^{*}$ & $.94 *$ & $.90 *$ & $.92 *$ & $.88 *$ & $.91 *$ \\
\hline & Flapless & $.95 *$ & $.93 *$ & $.86^{*}$ & $.96^{*}$ & $.94 *$ & $.93 *$ & $.86 *$ & $.96^{*}$ \\
\hline
\end{tabular}

*P is significant at $5 \%$

TABLE (2) Comparison of marginal bone loss between groups and implant surfaces at 6 and 12 months

\begin{tabular}{|c|c|c|c|c|c|}
\hline & \multicolumn{4}{|c|}{ Marginal bone loss after 6 months } & \multirow{3}{*}{$\begin{array}{c}\text { Independent t-test } \\
\text { Pvalue }\end{array}$} \\
\hline & \multicolumn{2}{|c|}{ Flap technique } & \multicolumn{2}{|c|}{ Flapless technique } & \\
\hline & $X$ & $S D$ & $X$ & $S D$ & \\
\hline Mesial & $.38 \mathrm{a}$ & .08 & $.25 \mathrm{a}$ & .05 & $.048 *$ \\
\hline Distal & $.48 \mathrm{a}$ & .21 & $.26 \mathrm{a}$ & .05 & $.003 *$ \\
\hline Buccal & $.36 \mathrm{a}$ & .13 & $.47 \mathrm{~b}$ & .21 & $.049 *$ \\
\hline Lingual & $.48 \mathrm{a}$ & .29 & $.26 \mathrm{a}$ & .05 & $.002 *$ \\
\hline Total & .42 & .20 & .31 & .14 & $.004 *$ \\
\hline \multirow[t]{2}{*}{ One- Way ANOVA } & \multicolumn{2}{|c|}{.194} & \multicolumn{2}{|c|}{$.006^{*}$} & \\
\hline & \multicolumn{4}{|c|}{ Marginal bone loss after 12 months } & \\
\hline Mesial & $1.05 \mathrm{a}$ & .52 & $.58 \mathrm{a}$ & .21 & $.001 *$ \\
\hline Distal & $.93 a$ & .24 & $.66 \mathrm{a}$ & .16 & $.029 *$ \\
\hline Buccal & $.68 \mathrm{~b}$ & .26 & $.89 \mathrm{~b}$ & .25 & $.047 *$ \\
\hline Lingual & $1.00 \mathrm{a}$ & .22 & $.55 \mathrm{a}$ & .08 & $.001 *$ \\
\hline Total & .91 & .35 & .67 & .22 & $.001 *$ \\
\hline One- Way ANOVA & \multicolumn{2}{|c|}{$.016^{*}$} & \multicolumn{2}{|c|}{$.027 *$} & \\
\hline
\end{tabular}

$X$; mean, SD; standard deviation, *p is significant at 5\% level. Different letters in the same column indicated a significant difference between implant surface (Tukey test<.05), while the same letters show a nonsignificant difference between implant surfaces

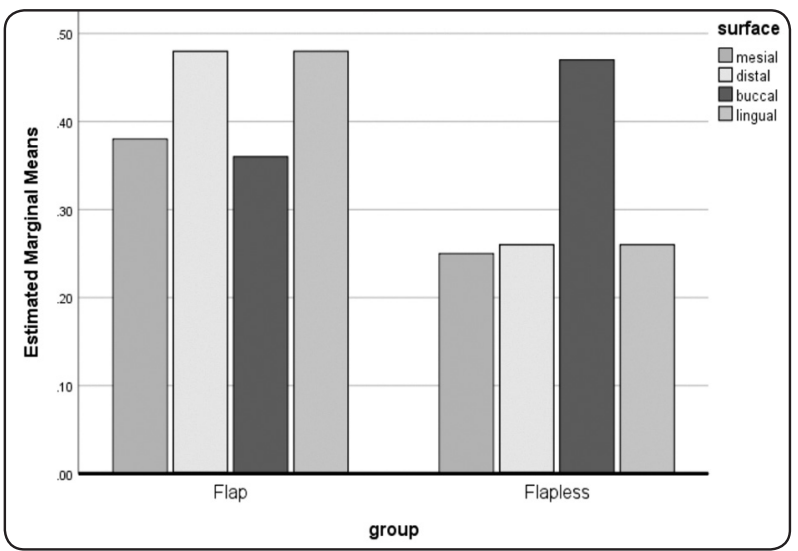

Fig. (4) Multiple comparison between implant surfaces for both groups after six months

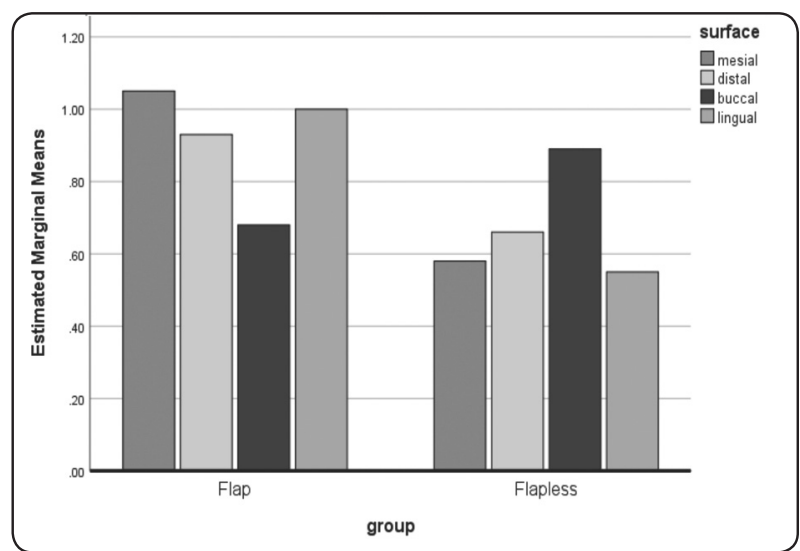

Fig. (5) Multiple comparison between implant surfaces for both groups after 12 months 


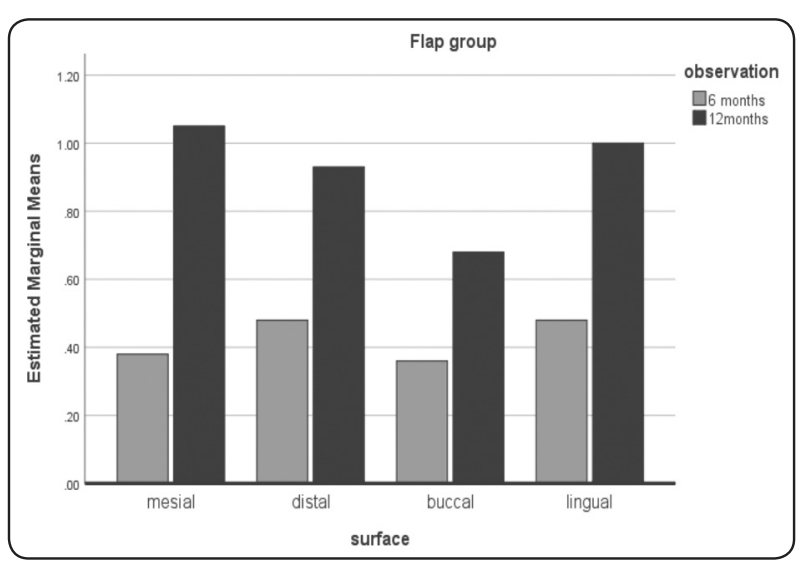

Fig. (6) Comparison of marginal bone loss between 6 and 12 months for all implant surfaces for flap group

\section{DISCUSSION}

In this study, bone loss was measured using cone beam CT instead of conventional periapical radiography as it provides Three-Dimensional information regarding bone resorption at labial and lingual the implant surfaces (in a cross-sectional images) in addition to mesial and distal surfaces (in panoramic images). Conversely, the periapical films are two dimensional which provides information on mesial and distal bone resorption only.

Also Cone beam CT is easily used with edentulous patients that had resorption of the ridge with elevated floor of the mouth which makes periapical radiographs difficult to perform ${ }^{24,25}$. The use of cone beam CT in evaluation of marginal bone resorption was previously described in other studies ${ }^{30,31}$. The survival rate was $90 \%$ and $100 \%$ survival rate in flap and flapless groups respectively. The failed implant and flap group was associated with peri-implantitis, mobility and pus formation. Failure occurred after implant loading. The implant was removed and the patient excluded from the study without affecting the results because the study was conducted according to "intention to treat principal". The cause of the implant failures in flap group may be attributed to the immediate loading with increased force transmission to the

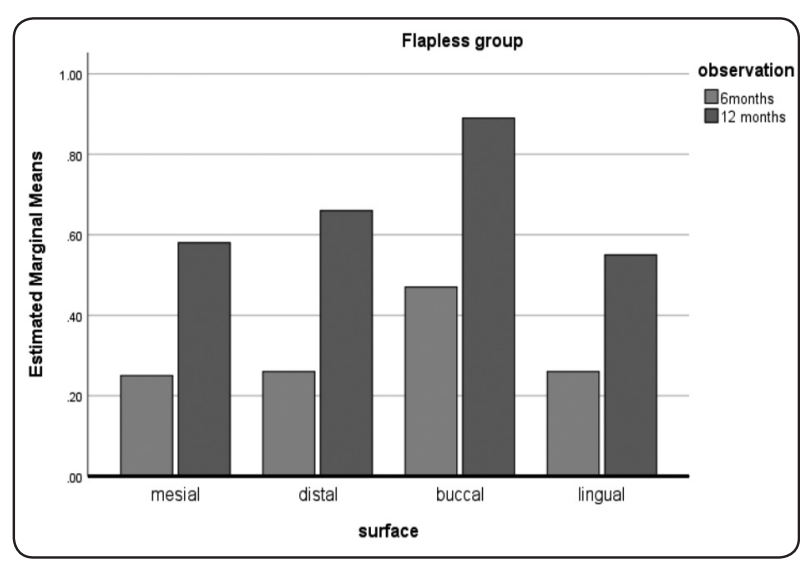

Fig. (7) Comparison of marginal bone loss between 6 and 12 months for all implant surfaces for flapless group

implants together with infection that may occur due to loosening of sutures and premature exposure of the implant areas.

During healing, excessive micromotion between the implant and the peri-implant bone can be a compromising factor ${ }^{32}$. For both groups, the mean marginal bone loss for all implant surfaces did not exceed $1 \mathrm{~mm}$ after one year. This amount of marginal bone loss is located in the normal range that was reported in earlier investigations ( less than $1.2 \mathrm{~mm}$ in the frist year) ${ }^{33}$. Despite immediate loading protocol used in this study may have a negative effect on marginal bone loss compared to delayed loading protocol ${ }^{26}$, the values of marginal bone loss was located in the normal limit. This could be attributed to the high initial stability of the implants (due to the high bone density in the interforaminal area) and the resiliency of locator attachments which allow vertical and hinge movement ${ }^{27,34,35}$.

The mean bone loss in flap group was significantly higher than flapless group after six and 12 months. The increased bone loss in flap group may be attributed to flap elevation, contact with oral microbial plaque, mucosal stripping, disruption to the periosteum which interferes with blood supply to the peri-implant bone compared to flap group ${ }^{36-38}$. This may reduce oxygen tension and activate 
osteoclast activity that may lead to increased bone resorption around implants ${ }^{36-38}$. The increased bone resorption around the flap group may be enhanced by the immediate loading protocol which cause increased load on the implants during initial healing when 2 unsplinted implants are planned to support immediately loaded mandibular overdentures ${ }^{39}$. Moreover, the dual (internal and externa) retention of locator and limited lateral and hinge movement ${ }^{40}$ may be responsible for transferring more loads to the implant, thus increasing bone loss. On the other hand, the flapless procedure reduced surgical time, have no sutures, minor or no swelling, with minimal postoperative discomfort. The bone remains covered by the periosteum, which may a positive effect on the early bone remodeling process, with slight changes in marginal bone loss, and improved clinical, radiographic, and immunologic outcomes compared with flap procedures ${ }^{41}$. In line with our observation, studies in another systematic review suggested that implants placed in healed sites with a flapless approach have better clinical parameters than the flapped procedure in a short-term follow$\mathrm{up}^{42}$. In contrast, the results of other studies suggest that both flap and flapless surgical approach had no difference in marginal bone loss despite the fact that they recommend the flapless approach considering its benefits ${ }^{16,43}$.

It is interesting in this study to find that the buccal surface of the implants is associated with the lowest marginal bone loss in flap group and the highest marginal bone loss in the flapless group after 12 months. The increased bone loss in the buccal surface in flapless group may be attributed to the mucosal supported surgical guide was used for implant placement. The compressibility of mucosa may cause a shift in implant position during the osteotomy preparation which is usually unnoticed as a technique is blind. Considering that mandibular dentures usually moves in labial direction because of inclination of occlusal plane, this slight movement may cause thinning of Labial bone around the implant and could be responsible for increased bone loss and the lingual aspect of the implants. Conversely, in the flap surgical approach, the bone is exposed and the surgeon can see the full anatomy of the alveolar ridge and keep the drill away from the labial bone. A similar observation was noticed in another study conducted on immediately loaded two implant retained mandibular overdentures with ball attachments ${ }^{44}$. The authors attributed the increased bone loss at labial sites to the increased bone strains. This explanation was in agreement with another ex vivo study ${ }^{39}$ for immediate loaded implants supporting overdentures

In this study, the bone loss increased significantly after 12 months compared to 6 months in both groups. This may be attributed to bone reaction to healing and reorganisation and increased occlusal load was time. This result was not surprising and in line with several studies that reported a continuous loss of marginal bone with time ${ }^{45}$

The limitations of this study include the small patient cohort and the short follow-up period. In addition, the lack of conventional loading protocol as a control group is also on the limitation. Therefore, future randomized controlled clinical trials are needed to ensure the long-term outcome of the present study and to compare immediate loading to conventional loading using both surgical techniques.

\section{CONCLUSION}

Within the limitations of this short-term study, the following conclusions could be achieved

- The flapless surgical approach is recommended for implant retained mandibular overdentures with locator attachments.

- The flapless approach was associated with reduced marginal bone loss after 12 months of denture insertion 


\section{REFERENCES}

1. Feine JS, Carlsson GE, Awad MA, Chehade A, Duncan WJ, Gizani S et al. The McGill Consensus Statement on Overdentures. Montreal, Quebec, Canada. May 24-25, 2002. Int J Prosthodont. 2002;15:413-4.

2. Thomason JM, Feine J, Exley C, Moynihan P, Muller F, Naert I et al. Mandibular two implant-supported overdentures as the first choice standard of care for edentulous patients--the York Consensus Statement. Br Dent J. 2009;207:185-6.

3. Ekfeldt A, Johansson LA, Isaksson S. Implant-supported overdenture therapy: a retrospective study. Int J Prosthodont. 1997;10:366-74.

4. Kobayashi M, Srinivasan M, Ammann P, Perriard J, Ohkubo C, Muller F et al. Effects of in vitro cyclic dislodging on retentive force and removal torque of three overdenture attachment systems. Clin Oral Implants Res. 2014;25:426-34.

5. Heckmann SM, Winter W, Meyer M, Weber HP, Wichmann MG. Overdenture attachment selection and the loading of implant and denture-bearing area. Part 2: A methodical study using five types of attachment. Clin Oral Implants Res. 2001;12:640-7.

6. Alsabeeha NH, Payne AG, Swain MV. Attachment systems for mandibular two-implant overdentures: a review of in vitro investigations on retention and wear features. Int $\mathrm{J}$ Prosthodont. 2009;22:429-40.

7. Trakas T, Michalakis K, Kang K, Hirayama H. Attachment systems for implant retained overdentures: a literature review. Implant Dent. 2006;15:24-34.

8. Evtimovska E, Masri R, Driscoll CF, Romberg E. The change in retentive values of locator attachments and hader clips over time. J Prosthodont. 2009;18:479-83.

9. Porter JA, Jr., Petropoulos VC, Brunski JB. Comparison of load distribution for implant overdenture attachments. Int J Oral Maxillofac Implants. 2002;17:651-62.

10. Heckmann SM, Schrott A, Graef F, Wichmann MG, Weber HP. Mandibular two-implant telescopic overdentures. Clin Oral Implants Res. 2004;15:560-9.

11. Kleis WK, Kammerer PW, Hartmann S, Al-Nawas B, Wagner W. A comparison of three different attachment systems for mandibular two-implant overdentures: oneyear report. Clin Implant Dent Relat Res. 2010;12:209-18.
12. Schneider AL, Kurtzman GM. Restoration of Divergent Free-standing Implants in the Maxilla. Journal of Oral Implantology. 2002;28:113-6.

13. Nguyen CT, Masri R, Driscoll CF, Romberg E. The Effect of Denture Cleansing Solutions on the Retention of Pink Locator Attachments: An in Vitro Study. Journal of Prosthodontics. 2010;19:226-30.

14. Alsiyabi AS, Felton DA, Cooper LF. The Role of Abutment-Attachment Selection in Resolving Inadequate Interarch Distance: A Clinical Report. J Prosthodontics. 2005;14:184-90.

15. ELsyad MA, Errabti HM, Mustafa AZ. Mandibular Denture Base Deformation with Locator and Ball Attachments of Implant-Retained Overdentures. J Prosthodont. 2016; 25:656-64

16. Prati C, Zamparini F, Scialabba VS, Gatto MR, Piattelli A, Montebugnoli L et al. A 3-Year Prospective Cohort Study on 132 Calcium Phosphate-Blasted Implants: Flap vs Flapless Technique. Int J Oral Maxillofac Implants. 2016;31:413-23.

17. Chrcanovic BR, Albrektsson T, Wennerberg A. Flapless versus conventional flapped dental implant surgery: a meta-analysis. PLoS One. 2014;9:e100624.

18. Rousseau P. Flapless and traditional dental implant surgery: an open, retrospective comparative study. J Oral Maxillofac Surg. 2010;68:2299-306.

19. Cannizzaro G, Leone M, Consolo U, Ferri V, Esposito M. Immediate functional loading of implants placed with flapless surgery versus conventional implants in partially edentulous patients: a 3-year randomized controlled clinical trial. Int J Oral Maxillofac Implants. 2008;23:867-75.

20. Cannizzaro G, Felice P, Leone M, Checchi V, Esposito M. Flapless versus open flap implant surgery in partially edentulous patients subjected to immediate loading: 1-year results from a split-mouth randomised controlled trial. Eur J Oral Implantol. 2011;4:177-88.

21. Romanos GE, Nentwig GH. Immediate versus delayed functional loading of implants in the posterior mandible: a 2-year prospective clinical study of 12 consecutive cases. Int J Periodontics Restorative Dent. 2006;26:459-69.

22. Turkyilmaz I, Sennerby L, Tumer C, Yenigul M, Avci M. Stability and marginal bone level measurements of unsplinted implants used for mandibular overdentures: a 1 -year randomized prospective clinical study comparing 
early and conventional loading protocols. Clin Oral Implants Res. 2006;17:501-5.

23. Albrektsson T, Buser D, Sennerby L. On crestal/marginal bone loss around dental implants. Int $\mathrm{J}$ Prosthodont. 2012;25:320-2.

24. Raes F, Renckens L, Aps J, Cosyn J, De Bruyn H. Reliability of circumferential bone level assessment around single implants in healed ridges and extraction sockets using cone beam CT. Clin Implant Dent Relat Res. 2013;15:661-72.

25. Naitoh M, Hayashi H, Tsukamoto N, Ariji E. Labial bone assessment surrounding dental implant using conebeam computed tomography: an in vitro study. Clin Oral Implants Res. 2012;23:970-4.

26. Elsyad MA, Elsaih EA, Khairallah AS. Marginal bone resorption around immediate and delayed loaded implants supporting a locator-retained mandibular overdenture. A 1-year randomised controlled trial. J Oral Rehabil. 2014;41:608-18.

27. Elsyad MA, Mahanna FF, Elshahat MA, Elshoukouki AH. Locators versus magnetic attachment effect on periimplant tissue health of immediate loaded two implants retaining a mandibular overdenture: a 1-year randomised trial. J Oral Rehabil. 2016;43:297-305.

28. Cawood JI, Howell RA. A classification of the edentulous jaws. Int J Oral Maxillofac Surg. 1988;17:232-6.

29. Lekholm U, Zarb G. Patient selection and preparation. In: Branemark PI, Zarb G, Albrektsson T, eds. Tissue integrated prosthesis: osseointegration in clinical dentistry. Chicago. Quintessence Publishing Co Inc. 1985:199-209.

30. Elsyad MA, Khirallah AS. Circumferential bone loss around splinted and nonsplinted immediately loaded implants retaining mandibular overdentures: A randomized controlled clinical trial using cone beam computed tomography. J Prosthet Dent. 2016;116 741-8

31. Razavi T, Palmer RM, Davies J, Wilson R, Palmer PJ. Accuracy of measuring the cortical bone thickness adjacent to dental implants using cone beam computed tomography. Clin Oral Implants Res. 2010;21:718-25.

32. De Smet E, Duyck J, Vander Sloten J, Jacobs R, Naert I. Timing of loading--immediate, early, or delayed--in the outcome of implants in the edentulous mandible: a prospective clinical trial. Int J Oral Maxillofac Implants. 2007;22:580-94.
33. Albrektsson T, Zarb G, Worthington P, Eriksson AR. The long-term efficacy of currently used dental implants: a review and proposed criteria of success. Int $\mathrm{J}$ Oral Maxillofac Implants. 1986;1:11-25.

34. Elsyad MA, Eltowery SM, Gebreel AA. Peri-implant strain around mesially inclined two-implant-retained mandibular overdentures with Locator attachments. J Oral Sci. 2017;59:483-90.

35. ElSyad MA, Denewar BA, Elsaih EA. Clinical and Radiographic Evaluation of Bar, Telescopic, and Locator Attachments for Implant-Stabilized Overdentures in Patients with Mandibular Atrophied Ridges: A Randomized Controlled Clinical Trial. Int J Oral Maxillofac Implants. 2018;33:1103-11.

36. Ahn MR, An KM, Choi JH, Sohn DS. Immediate loading with mini dental implants in the fully edentulous mandible. Implant Dent. 2004;13:367-72.

37. Bulard RA, Vance JB. Multi-clinic evaluation using minidental implants for long-term denture stabilization: a preliminary biometric evaluation. Compend Contin Educ Dent. 2005;26:892-7.

38. Jeong SM, Choi BH, Li J, Kim HS, Ko CY, Jung JH et al. Flapless implant surgery: an experimental study. Oral Surg Oral Med Oral Pathol Oral Radiol Endod. 2007;104:24-8.

39. Akca K, Akkocaoglu M, Comert A, Tekdemir I, Cehreli MC. Bone strains around immediately loaded implants supporting mandibular overdentures in human cadavers. Int J Oral Maxillofac Implants. 2007;22:101-9.

40. Chikunov I, Doan P, Vahidi F. Implant-retained partial overdenture with resilient attachments. J Prosthodont. 2008;17:141-8.

41. Tsoukaki M, Kalpidis CD, Sakellari D, Tsalikis L, Mikrogiorgis G, Konstantinidis A. Clinical, radiographic, microbiological, and immunological outcomes of flapped vs. flapless dental implants: a prospective randomized controlled clinical trial. Clin Oral Implants Res. 2013; 24:969-76.

42. Llamas-Monteagudo O, Girbes-Ballester P, Vina-Almunia J, Penarrocha-Oltra D, Penarrocha-Diago M. Clinical parameters of implants placed in healed sites using flapped and flapless techniques: A systematic review. Med Oral Patol Oral Cir Bucal. 2017;22:e572-e81.

43. Gamborena I, Lee J, Fiorini T, Wenzel BA, Schupbach P, Wikesjo UM et al. Effect of Platform Shift/Switch and 
Concave Abutments on Crestal Bone Levels and Mucosal Profile following Flap and Flapless Implant Surgery. Clin Implant Dent Relat Res. 2015;17:908-16.

44. Elsyad MA, Al-Mahdy YF, Fouad MM. Marginal bone loss adjacent to conventional and immediate loaded two implants supporting a ball-retained mandibular overdenture: a 3-year randomized clinical trial. Clin Oral Implants Res. 2012;23:496-503.

45. Lang NP, Pun L, Lau KY, Li KY, Wong MC. A systematic review on survival and success rates of implants placed immediately into fresh extraction sockets after at least 1 year. Clin Oral Implants Res. 2012;23 Suppl 5:39-66. 